\title{
Un concurs Joc de Vries per treballar la Taula Periòdica
}

Sara Fabregat Fabregat (fabregat.sara@gmail.com) Màster Universitari en Professor/a d'Educació Secundària Obligatòria i Batxillerat, Formació Professional i Ensenyaments d'ldiomes.

Llorenç Monferrer Pons (monfer@uji.es) IES Professor Broch i Llop (Vila-real).

En aquest article es presenta una proposta educativa implementada en l'assignatura de Física i Química del tercer curs d'ESO a I'IES Politècnic de Castelló de la Plana la qual està inclosa en un Treball Final del Màster Universitari en Professor/a d'Educació Secundària Obligatòria i Batxillerat, Formació Professional i Ensenyaments d'ldiomes de la Universitat Jaume I de Castelló. Amb l'objectiu principal d'aconseguir una millora educativa s'ha fet ús de la metodologia de la Investigació-acció amb l'ajut de tècniques d'aprenentatge col-laboratiu. De l'observació directa de les classes, de la consulta tant dels expedients dels alumnes com de la llibreta de notes de la tutora i, després d'haver realitzat una enquesta als estudiants es va concloure que la falta de motivació $i$ de participació d'alguns d'ells a les classes de Física i Química era un problema a corregir. La idea general és incrementar tant la participació com la motivació dels alumnes en l'estudi de la Taula Periòdica dels Elements mitjançant un Joc Concurs de De Vries. Les activitats de la present proposta han estat avaluades per part dels estudiants amb qüestionaris $i$ enquestes. La resposta dels alumnes davant aquesta manera de treballar ha sigut positiva, les activitats han tingut molta acceptació i s'han aconseguit, en quasi tots els casos, els objectius proposats.

Paraules clau: Física i Química, Motivació, Participació, Investigació-acció, Joc Concurs de De Vries.

The educational proposal presented in this article was implemented at IES Politècnic in Castelló de la Plana in the third curse of ESO. It was created as a Final Paper for the Master in Secundary Education for Teacher given at University Jaume I in Castelló. In order to get an educational improvement, investigation-action methodology has been used taking into account collaborative learning. After a direct classroom observations, having checked the teacher's notes and after having analyzed the results of the survey answered by the students, we can conclude by saying that the lack of motivation and participation of some students on chemistry classes was a problem that needed to be solved. The main purpose of this educational proposal is to increase both participation and motivations of the students in the study of Periodic Table through a game named De-Vries. All the activities presented in this proposal have been evaluated by students through questionnaires and surveys. This way of working has been answered positively by the students. The activities proposed been highly accepted and the main objectives have often been achieved.

Keywords: Physics and Chemistry, Motivation, Participation, Research-Action, Game Contest De Vries. 


\section{INTRODUCCIÓ}

El present treball recull una proposta educativa que es va implementar amb alumnes de $3 r$ d'ESO en l'assignatura de Física i Química a l'IES Politècnic de Castelló de la Plana. Amb l'objectiu principal d'aconseguir una millora educativa s'ha fet ús de la metodologia de la Investigació-acció. Aquesta metodologia consta de diverses fases (Figura 1):

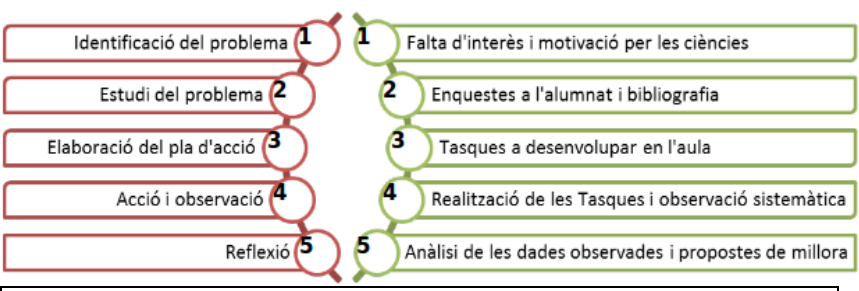

Figura 1. Esquema on apareixen les fases de la metodologia de la Investigació-Acció.

Es tracta d'un procés cíclic d'acció i reflexió. Primer, cal analitzar la pràctica docent i identificar l'àrea de millora. Tot seguit, s'ha de planificar (pla d'acció) com es durà a terme i quina o quines seran les metodologies a emprar que ens ajudaran a resoldre el problema detectat. Després, posar el procés en pràctica (acció) al mateix temps que s'observen i anoten els resultats que es van obtenint i es modifica en el moment, si s'escau, allò que s'està observant que puga millorar l'acció. A continuació s'ha de fer una anàlisi dels resultats i reflexionar sobre quines millores es podrien aportar. Finalment, torna a començar el cicle treballant amb les millores proposades. Segons Marqués i Ferrández-Berrueco (2011), "La investigació-acció comporta la comprovació d'idees en la pràctica com a mitjà per a millorar les condicions socials i incrementar, al mateix temps, el coneixement". En l'acció es desenvoluparan dues activitats que incorporen Tècniques d'Aprenentatge Col•laboratiu (TAC) com "Pensa, forma una parella i comenta" i "Joc Concurs de De Vries". Les activitats es presentaran a través de la plataforma virtual Google Sites per tal d'implementar l'acció.

En el llibre "Técnicas de aprendizaje colaborativo" (Barkley, 2007) es defineixen les TAC com a diferents formes de treballar en parelles o en xicotets grups de forma cooperativa amb uns objectius d'aprenentatge comuns. En aquesta nova forma d'organitzar les classes el paper del docent és summament important, ja que és el responsable de buscar una intencionalitat en el disseny de les activitats i la seva estructuració (Monferrer \& Forcano, 2014). Al llarg dels anys s'ha demostrat que aquesta forma de treballar incrementa la satisfacció dels alumnes amb la matèria d'estudi (Domingo, 2008). A més a més, hi ha diferents projectes sobre xicotets grups d'estudiants que treballen conjuntament derivant en millores notables en el seu rendiment acadèmic (Pascarella \& Terenzini, 1991).

Kagan i High (2002) consideren que hi ha quatre principis bàsics que conformen els equips col-laboratius. En primer lloc parlen d'una Interdependència positiva. Aquest principi fa referència a la necessitat de cada membre del grup de preocupar-se per l'aprenentatge de la resta de companys amb la fi d'aconseguir els objectius, i no només preocupar-se pel seu rendiment propi. El segon principi que remarquen Kagan i High és la Responsabilitat individual i corresponsabilitat, és a dir, en els equips, cadascun dels membres rep retroalimentació relativa al propi progrés, al dels altres i al grup sencer. El tercer principi parla de La participació igualitària, remarcant que és imprescindible que cadascun dels membres dels equips tinguen les mateixes oportunitats de participar i aportar a l'equip. Per últim, fan referència a una Interacció simultània, assenyalant la participació alhora del major nombre de membres del grup. Aquests interactuen entre ells i decideixen quina és la millor manera d'abordar l'activitat que els ha sigut proposada.

Pujolàs(2003), al seu quadern, que porta per nom "El aprendizaje cooperativo: algunas ideas prácticas", explica quina és la manera més adequada de formar els equips de treball. Remarca que els equips han de ser heterogenis i permanents. Comenta que el nombre ideal de membres estaria en quatre. També recomana tenir en compte les possibles incompatibilitats i preferències.

La integració de les Tecnologies d'informació i Comunicació (TIC) en l'ensenyament de les ciències d'una manera adequada pot motivar els estudiants en activitats d'aprenentatge significatiu, incrementar notablement la seva participació i millorar el seu pensament crític (Waldegg, 2002). Així doncs, la plataforma Google Sites per presentar les activitats als estudiants, és una ferramenta que permet crear espais de comunicació idonis per al desenvolupament d'una nova forma d'alfabetització tecnològica crítica, col-laborativa i creativa (Bruns \& Humphreys, 2005). 


\section{OBJECTIUS}

L'objectiu que volem assolir per tal d'aconseguir la nostra millora educativa és:

- Incrementar tant la participació com la motivació dels alumnes en les classes de Física i Química i fer que els alumnes relacionen allò que estan estudiant amb la seva vida quotidiana.

Tenint açò present en tot moment, les activitats que s'han proposat en aquesta experiència educativa han de complir els objectius (segons el Decret 112/2007, de 20 de juliol, del Consell, pel qual s'estableix el currículum de l'Educació Secundària Obligatòria a la Comunitat Valenciana) relacionats amb els continguts "Els elements de la Taula Periòdica" els quals han servit com a plataforma per poder dur a terme l'acció.

- Distingir entre element i compost químic.

- Aprendre a classificar els elements en metalls, no metalls i gasos nobles.

- Conèixer el criteri de classificació dels elements en el sistema periòdic.

- Identificar els grups d'elements més importants.

- Conèixer els símbols dels elements

\section{PROPOSTA}

\section{Descripció de la problemàtica}

La primera part de la metodologia de la "Investigació-acció" és identificar l'àrea que es vol millorar. Per aconseguir-ho es va fer ús d'una sèrie d'indicadors i recursos que ajudaren a detectar-la. Així:

1) Es va parlar amb la professora que imparteix aquesta assignatura per comentar anècdotes $i$ situacions que ella havia observat durant les seves classes. També es va tenir la possibilitat d'accedir a la seva llibreta de notes. En resum, la professora manifesta que els estudiants no participen activament en les classes i, a més, mostren manca d'interès per l'assignatura.

2) Segons Barrado, Gallego i Valero-García (1999), les enquestes ajuden a extraure informació dels nostres alumnes i poden beneficiar i millorar la nostra pràctica docent. Així, es va passar, a un total de 62 alumnes, una senzilla enquesta (fig. 2) preguntant sobre l'assignatura de Física i Química
1. T'agrada aquesta assignatura?

2. Participes en les activitats que proposa la professora? Fas els deures? Per què?

3. Per què penses que esta assignatura ès important? O per què no?

4. Proposa activitats que f'agradaria realitzar en aquesta assignatura.

Figura 2: Enquesta que es va passar als 62 alumnes preguntant sobre l'assignatura de Física i Química.

De les respostes a l'enquesta se'n dedueix que:

- Un $40 \%$ afirmen que no els agrada l'assignatura.

- Un $18 \%$ afirmen que no participen a classe i que no realitzen les activitats proposades per la professora. Un $16 \%$ diu que només ho fa a voltes. Aquests dos grups d'alumnes argumenten que és perquè no entenen allò que s'ha de fer i perquè és molt difícil i/o els avorreix. El $66 \%$ restant afirma participar i fer els deures sempre. Però, només un $32 \%$ afirma fer-ho per millorar i per entendre millor l'assignatura. La resta, un $68 \%$ diu participar perquè es veu obligat per aprovar l'assignatura o per pujar nota.

- Un 54\% (la resta no fa cap comentari) pensen que aquesta assignatura no és de gran importància. Els motius que ells aporten són entre d'altres:

"Si no vols ser científic no et val per a res"; "No és tan important com altres assignatures"; "No entenc per a què serveix"

- Com a resposta al punt 4 quasi tots el alumnes proposen el mateix, fer experiments al laboratori.

Aquests resultats el que constaten és que l'assignatura els resulta complicada, que sovint en no relacionar-la amb aspectes de la seua vida quotidiana, els resulta avorrida i que només participen per obligació no perquè els agrade 0 tinguen curiositat.

Sobre l'avorriment i la falta de relació amb la vida quotidiana d'allò que s'explica a classe parlen Graciela i Sánchez (2010):

"Els joves no li troben sentit a allò que aprenen a l'escola quan no ho apliquen de manera immediata en les seves vides. Així, no li troben valor a aquest coneixement i els causa avorriment. Els docents participem directament en aquesta desvinculació de l'escola amb la vida quotidiana 
quan impartim classes descontextualitzades les quals no signifiquen res per als estudiants.(p.9)".

A la Universitat de Sevilla, han realitzat un estudi sobre els obstacles que dificulten la participació dels estudiants a classe, concloent que factors com la motivació, l'organització a l'aula i la no improvisació de les classes, entre d'altres, poden millorar aquest aspecte (Fernández, 2010).

\section{Pla d'acció}

Per a poder abordar la problemàtica s'han dissenyat dues activitats basades majoritàriament en dues TAC. La primera activitat es basa en la tècnica "Pensa, forma una parella i comenta", és una de les TAC que es troba al llibre "Técnicas de aprendizaje colaborativo" (Barkley 2007). Aquesta consisteix a formular preguntes als alumnes amb l'objectiu que les pensen, les comenten en parelles i finalment facen una posada en comú davant dels seus companys. El component "pensa" requereix que els estudiants es detinguen i reflexionen abans de parlar, donant-los així una oportunitat per reunir i organitzar els seus pensaments. Els components "forma una parella i comenta" animen els alumnes a cooperar i a contrastar les seues idees amb les d'un altre company i a assajar la seua resposta primer en una situació de poc perill abans de presentar-la en públic davant tota la classe. Amb açò s'aconsegueix la millora de la qualitat de les aportacions dels estudiants a classe $i$, en general, augmenta la voluntat i la bona disposició de parlar davant del grup. Hi ha autors que opinen que és molt important relacionar la ciència que s'ensenya a les classes amb la vida quotidiana per a augmentar l'interès dels alumnes (Neff i altres, 2010). És per aquest motiu que s'ha pensat d'apropar els continguts del currículum als alumnes amb una lectura d'un text que parla d'on podem trobar els elements químics en un supermercat.

La segona activitat 0 activitat principal, està basada en el Joc Concurs de De Vries. Aquesta tècnica, tal com expliquen Moliner, Sanchiz i Sales (2009) és aplicable a totes les edats i a totes les matèries curriculars. Es formen grups heterogenis atenent al nivell de rendiment dels alumnes. Després la professora presenta als alumnes el material que han d'estudiar, dividit en temes-lliçons. Abans de començar el Joc Concurs cada grup treballa per garantir que tots els membres se sàpiguen bé el tema-lliçó. Finalment, es realitzen "tornejos acadèmics". En aquests, estudiants de cada equip s'enfronten als membres de la resta d'equips que tenen similars nivells de rendiment. Els participants han de guanyar punts per als seus respectius equips. Tots els membres del grup han de tindre les mateixes oportunitats de participar i així poder aportar punts al grup.

\section{Acció i observació}

Els destinataris de la nostra acció han estat un total de 62 alumnes de $3 r$ d'ESO de tres grups diferents $(A, B$ i $C)$. La majoria compleixen enguany 15 anys encara que també hi ha alumnes repetidors que enguany fan 16 i 17 anys. El conjunt dels alumnes és del tot divers pel que fa tant a l'aprenentatge com al comportament a classe. Al voltant d'un $25 \%$ dels alumnes són immigrants, sent el nivell de coneixements d'alguns d'ells deficient, possiblement degut a la recent incorporació al sistema educatiu i a l'aprenentatge recent de l'idioma.

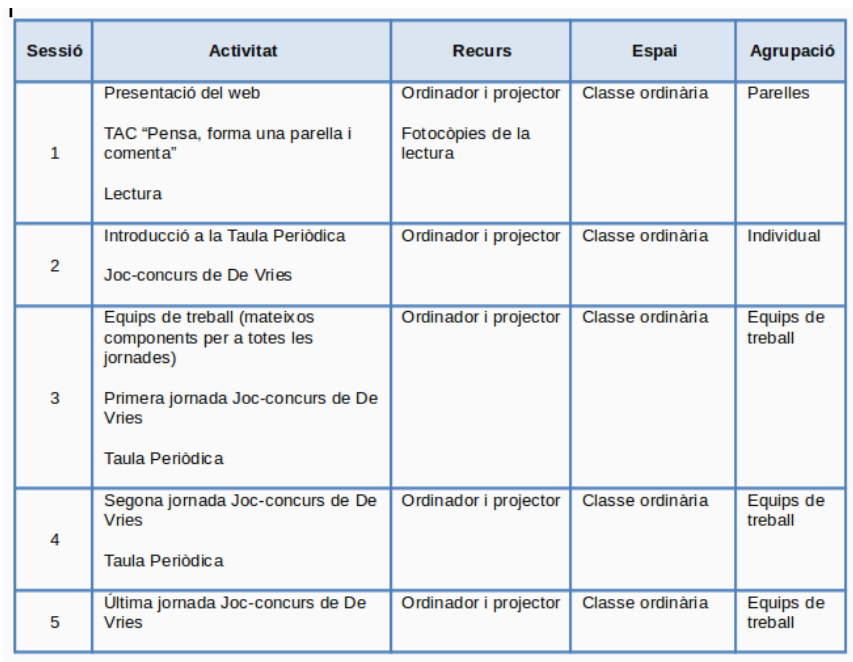

Figura 3. Taula en la que es mostra l'acció que s'ha implementat a l'aula.

Tenint en compte aquestes $i$ altres consideracions, s'ha elaborat l'acció la qual s'ha implementat en cinc sessions de 50 minuts cadascuna (Figura 3 ). Aquesta està recollida en un lloc web anomenat "Parlem d'elements químics..." [1]. El web té dos apartats diferenciats centrats en l'alumnat, que es poden trobar al lateral esquerre de la pantalla. Un d'ells disposa de pàgines enfocades a la consulta dels alumnes i dedicades a explicar cadascuna de les activitats (sessions que ocupen, material necessari, rúbriques d'avaluació, qüestionaris d'avaluació de l'activitat, passes a seguir per realitzar-les...). L'altre apartat anomenat "guia del professor" està dividit en diferents pàgines que aporten informació sobre els objectius i continguts de la física i la química emprats per fer les activitats, competències bàsiques, metodologia emprada, pla d'avaluació... Els alumnes tenen accés a tot el web des del començament de l'acció i els pot servir d'ajuda a l'hora de preparar-se les 
classes, obtindre informació sobre com seran avaluats... A més, mitjançant els qüestionaris en línia poden avaluar les activitats que han realitzat perquè puguen ser millorades.

\section{Activitat 1. De compres amb la taula periòdica [2]}

Aquesta activitat es du a terme en una única sessió i està dividida en dues parts. En primer lloc, per tal d'introduir la unitat dels "Elements Químics" els alumnes hauran de contestar unes preguntes per indagar en els seus coneixements previs sobre els elements químics. Quins en coneixen i on els poden trobar. Durant el període d'observació de les classes es va observar com els estudiants no treballaven mai en grup. Doncs, per tal d'introduirlos en aquestes dinàmiques es va pensar que contestaren tres preguntes mitjançant la TAC " Pensa, forma una parella i comenta". El procediment que se'ls va proposar va ser el següent:

- Llegeix les preguntes individualment.

- Pensa les respostes i escriu-les a la llibreta.

- Quan tingues clares les teues respostes, busca una parella per comentar-les.

- Quan ja tingues la teua parella, comenteu les respostes. Primer explicarà un membre de la parella el que ha contestat. Quan el primer haja acabat comentarà les respostes el segon.

- Si les preguntes es complementen, heu de completar la informació en la llibreta. Si són contradictòries heu d'aplegar a un acord.

- Finalment, les comentarem tots junts

A continuació es procedeix a realitzar una lectura d'un text sobre un recorregut per un supermercat destacant en cada secció quins elements químics podem trobar. Cada alumne té el text en paper i realitza la lectura de manera individual. Després es posa en comú allò que més els ha sorprès i agradat. Per a casa, cada alumne ha de contestar unes preguntes referents al text. Les respostes seran recollides per la professora.

Cadascun dels apartats en què es divideix aquesta activitat serà avaluat amb la rúbrica d'avaluació de l'activitat 1 que apareix al web.

\section{Activitat 2. Ens pose a prova [3]}

Aquesta activitat es du a terme en 4 sessions.

Sessió 1. La professora introdueix la Taula Periòdica i les tres grans zones en què està dividida. Finalment, comença amb l'estudi de tres dels grups representatius: alcalins, alcalinoterris i terris. Al final de la classe s'explica en què consisteix el Joc Concurs de De Vries el qual es realitzarà a la següent sessió.

1) La professora dividirà la classe en grups heterogenis de cinc persones (Figura 4). Cada lletra associada a un alumne simbolitza un nivell de rendiment $(a>b>c>d>e)$. Així, en cada classe hi ha tants grups com es poden fer depenent del nombre d'alumnes de la classe. Però, en conjunt tots els grups tindran un nivell de rendiment semblant.

\begin{tabular}{|c|c|c|c|c|c|}
\hline GRUP 1 & 1a & $1 \mathrm{~b}$ & $1 \mathrm{c}$ & $1 d$ & $1 \mathrm{e}$ \\
\hline GRUP 2 & $2 a$ & $2 b$ & $2 c$ & $2 d$ & $2 \mathrm{e}$ \\
\hline GRUP 3 & $3 a$ & $3 b$ & $3 c$ & $3 d$ & $3 e$ \\
\hline GRUP 4 & $4 a$ & $4 b$ & $4 c$ & $4 d$ & $4 e$ \\
\hline GRUP 5 & $5 a$ & $5 b$ & $5 c$ & $5 d$ & $5 e$ \\
\hline Ronda 1 & $1 \mathrm{a}$ & $2 a$ & $3 a$ & $4 a$ & $5 a$ \\
\hline Ronda 2 & $1 \mathrm{~b}$ & $2 b$ & $3 b$ & $4 b$ & $5 b$ \\
\hline Ronda 3 & $1 c$ & $2 c$ & $3 c$ & $4 c$ & $5 c$ \\
\hline Ronda 4 & $1 d$ & $2 d$ & $3 d$ & $4 d$ & $5 d$ \\
\hline Ronda 5 & $1 \mathrm{e}$ & $2 e$ & $3 e$ & $4 e$ & $5 e$ \\
\hline
\end{tabular}

Figura 4. Distribució dels alumnes en grups heterogenis.

2) Cada grup es reunirà i repassarà tots els aspectes estudiats a la sessió anterior sobre la Taula Periòdica, assegurant-se que cap membre del grup tinga dubtes. Com que la puntuació del Joc Concurs serà la mateixa per a tots els membres del mateix grup, caldrà que els alumnes posen especial atenció a aquest punt.

3) A continuació començarà el Joc Concurs de De Vries. Eixirà un representat de cada grup, ronda 1. La professora farà una pregunta al membre del primer grup. Si aquesta persona la respon bé, se li sumarà un punt. En cas que la resposta no siga correcta hi haurà un rebot per al membre del grup del costat. Si encerta, sumarà mig punt. Si falla ja no hi haurà possibilitat de rebot.

4) Una volta el primer grup haurà tingut la seua pregunta la professora en realitzarà una altra per al segon grup. La metodologia és la mateixa, si encerta, un punt, i si falla hi ha rebot. I així fins que passe tota la primera ronda de participants.

5) Una volta ha passat la primera ronda, començarem amb uns altres representants de cada grup i s'aplicarà la mateixa metodologia.

6) El concurs s'acaba quan tots el membres dels grups hi han participat.

Sessió 2. Aquesta sessió comença amb el primer Joc Concurs. En finalitzar la sessió, la professora explica els tres grups següents de la 
taula periòdica que hauran d'estudiar per al dia següent. En aquest cas són els grups 14, 15 i 16.

Sessió 3. En aquesta sessió es realitza el mateix que a l'anterior. En primer lloc, es fa el Joc Concurs, on entren preguntes de tots els grups que han estudiat fins al moment. Després s'explica la resta de grups de la Taula Periòdica que s'ha programat treballar, el 17, 18 i principals metalls de transició.

Sessió 4. En aquesta sessió es realitza l'última jornada del Joc Concurs on es preguntarà sobre qualsevol dels elements estudiats.

Pel que fa a l'avaluació, aquesta activitat val un $70 \%$ del total de les activitats plantejades en l'acció. Aquest percentatge es divideix en tres parts iguals, una per cada jornada de Joc Concurs de De Vries. Si l'equip encerta totes les preguntes tindrà el percentatge complet corresponent a la jornada. En cas contrari, tindrà la part proporcional.

\section{AVALUACIÓ DE LA PROPOSTA}

Per poder fer un seguiment de com s'anava desenvolupant el projecte, en cadascuna de les classes es van fer diferents tipus d'observacions. S'han tingut en compte les recomanacions de Blández (1995), que diu que ha d'haver-hi una triangulació tant en persones com en mètodes a l'hora de fer l'avaluació.

Per tant, durant la realització de les activitats, s'ha escrit un diari de l'investigador anotant allò més rellevant i significatiu que ha ocorregut en cadascuna de les sessions referent a la metodologia i a les reaccions dels alumnes davant la mateixa. Per una altra banda, els alumnes han contestat un qüestionari en finalitzar cada activitat. Finalment també es van recollir les observacions dutes a terme per la tutora de l'IES.

\section{Activitat 1. De compres amb la taula periòdica}

\section{- Diari de l'investigador}

En el primer grup on es va implementar la TAC, l'acceptació dels alumnes no va ser massa bona. No van seguir les passes corresponents i es van posar a comentar les preguntes directament. Va ser necessari insistir molt per formar les parelles $\mathrm{i}$ posar-se a treballar, especialment amb aquells alumnes que per costum mai participen a les classes. Per això, en els següent grups es va introduir una modificació en la manera de procedir. Primer que res es van organitzar les parelles i una vegada asseguts es van explicar totes les passes a seguir. Aquesta modificació inicial va facilitar el desenvolupament de l'activitat. Tots els alumnes van participar, fins $i$ tot aquells que no solen col-laborar a classe van acabar gaudint de l'activitat. Cas anecdòtic, en sentit molt positiu, va ser el d'un estudiant que mai participava a les classes. En un principi, l'estudiant amb la qual es va emparellar va mostrar una reacció d'incomoditat. Però, després d'insistir una mica es van posar a treballar. Doncs, allò més sorprenent va ser que a l'hora de comentar les preguntes en veu alta l'esmentat estudiant va alçar voluntàriament la mà i va ser ell qui va començar amb aquesta part final de la TAC.

Pel que fa a la lectura, tots els alumnes, sense cap excepció, van participar en la posterior posada en comú i van mostrar la seua sorpresa amb alguns aspectes de la lectura. Aquesta bona predisposició a participar a classe pot ser una conseqüència de la introducció a l'aula del treball colølaboratiu.

\section{- Qüestionari en línia [4]}

Tota l'activitat ha sigut avaluada per part de l'alumnat amb el seu corresponent qüestionari en línia. Exceptuant la valoració personal final es tracta d'un qüestionari de resposta tancada on el tipus de pregunta està graduada segons l'escala Likert: l'alumne ha de puntuar cada qüestió de l'1 (totalment en desacord) al 5 (totalment d'acord). Cal dir, que encara que en un principi els qüestionaris s'han plantejat per respondre'ls en línia, la realitat és que als alumnes de tots els grups els costava molt entrar a la pàgina web per respondre'ls. Aleshores es va optar per donar els qüestionaris en paper. Els resultats d'aquest qüestionari poden veure's a la Figura 5.

En general l'acceptació de l'activitat ha sigut bona. Així, un $85 \%$ ha contestat que li ha agradat fer aquesta TAC, que els ha agradat treballar conjuntament i pensen que els ha ajudat el fet de comentar les preguntes amb el company.

Alguns dels comentaris recollits en la part de la valoració personal han estat:

- "Me ha gustado, la clase se me ha pasado corta y entretenida. También he aprendido elementos químicos que no sabía que estaban en los alimentos".

- "A mi personalment m'ha agradat molt".

- "M'ha agradat parlar amb la meua companya sobre les respostes $i$ així poder comparar-les".

- "M'ha agradat poder comentar les respostes amb uns altres companys, ja 


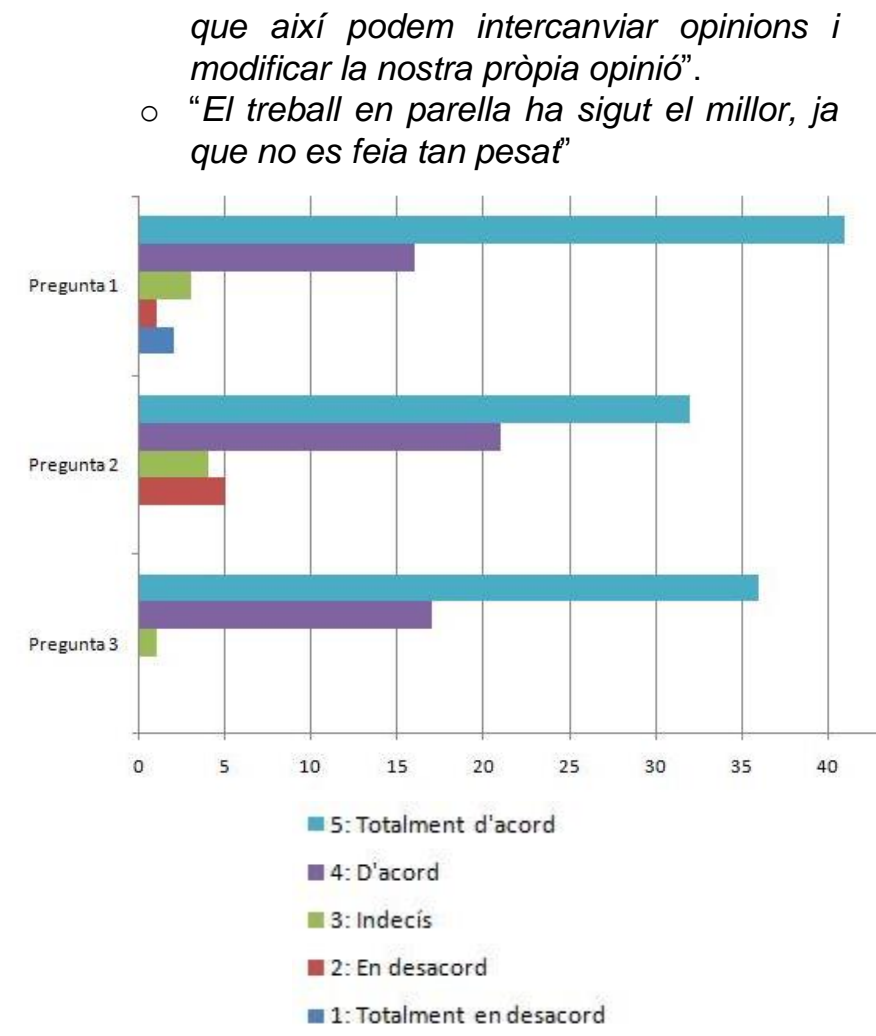

Figura 5. Gràfic de barres amb els resultats del qüestionari en línia als alumnes en relació a l'activitat 1.

- Observació de la tutora IES:

Les observacions fetes per la tutora són coincidents amb allò que s'ha explicat al diari de l'investigador. Sota el seu punt de vista, ha hagut una millora en la participació.

\section{Activitat 2. Ens hi posem a prova}

- Diari de l'investigador

Les sensacions anotades al diari de l'investigador són pràcticament iguals per als tres grups (A, B, C). El dia que se'ls va explicar en què consistia el Joc Concurs diversos alumnes, just aquells que sempre solen treballar a classe i trauen bones notes, van protestar. Argumentaven que no era just que la nota fóra per a tot l'equip igual, independentment de si havien contestat bé o no. Els grups havien estat organitzats amb l'ajuda de la tutora tenint en compte el grau de capacitat dels diferents alumnes i també de les relacions que hi havia entre ells, la qual cosa va ser acceptada des d'un primer moment.

El dia en què es realitzava el primer concurs, els alumnes que no havien estudiat estaven un poc nerviosos pensant que haurien de sortir d'un en un per contestar les preguntes. En deixar-los repassar durant els primers minuts, es va observar clarament com els grups començaven a funcionar. Les persones que no havien estudiat s'esforçaven a fer-ho i els que sí que havien estudiat ajudaven els primers. Es pot afirmar que, malgrat els dubtes inicials manifestats pels estudiants, tots els equips van treballar correctament.

Una volta va començar el Joc Concurs l'ambient a les aules va ser molt bo. Els membres dels equips s'animaven entre ells $i$ tots estaven atents a les respostes dels companys. Cal dir que tots els alumnes van encertar totes les preguntes. Açò el que demostra és que el treball en equip va funcionar i que entre tots van aconseguir els seus objectius. A mesura que avançàvem en les jornades millorava el funcionament del concurs. Els estudiants venien més preparats i s'organitzaven millor. Només entrar a classe seien per grups i començaven a repassar sense que fera falta dir-ho. Tots aportaven les seves experiències o maneres amb les quals havien estudiat, com per exemple les regles mnemotècniques que cadascú havia inventat.

\section{- Qüestionari en línia [5]}

Els resultats d'aquest qüestionari es poden veure a la figura 6 . Els alumnes en les seves respostes posen de manifest que aquesta tècnica de treball col-laboratiu ha tingut molt bona acceptació i els ha permès augmentar la seva participació i el seu aprofitament de les classes. Així, la majoria estan d'acord que el Joc Concurs ha fet que la gran majoria estudiaren abans d'anar a classe. A més, un $95 \%$ dels alumnes afirmen que els ha resultat profitós reunir-se amb els seus companys d'equip per repassar els continguts abans de la competició. Més d'un 95\% han respost que pensen que aquesta dinàmica és una bona manera de repassar allò que s'ha treballat a l'aula. El $100 \%$ dels alumnes voldrien repetir aquesta metodologia i, més d'un $95 \%$ confirmen que aquesta manera de treballar ha fet que augmentara la seua participació a classe.

Els comentaris que han posat a la pregunta sis del qüestionari són tots, sense excepció, positius. A continuació es mostren les transcripcions d'alguns d'ells:

- "Así es más fácil aprender porque es como un juego y te es más divertido. Estudiar en grupo es más sencillo"

- "Es entretingut, més que fer classe normal de física i química. El treball en 
grup es millor perque si no saps alguna cosa el teu company te pot ajudar"

- "Ha sigut divertit, però seria més divertit en més elements i més llarg"

- "A sigut molt divertit i e apres més del que pensava, la professora ha fet la clase molt divertida"

- "No me lo sabia y con la tonteria me lo he aprendido, esta bien el juego"

- "M'ha paregut molt útil perque entre tots és més fàcil obtindre bons resultats. Aquesta tècnica fa que entre tots ens ajudem. M'agradat molt"

- "M'ha paregut un gran joc ja que ha servit per a prendre més i ajudar-nos els uns als altres. M'agradaria fer més jocs així. Els cinc minuts han servit per a repassar més"

- "L'activitat $m$ 'ha agradat molt ja que si ho fem en grup és més entretingut $i$ si tots aporten alguna cosa hi ha menys probabilitat d'equivocar-nos"

- Observació de la tutora IES:

Les observacions fetes per la professora constaten que l'activitat s'ha dut a terme amb èxit.

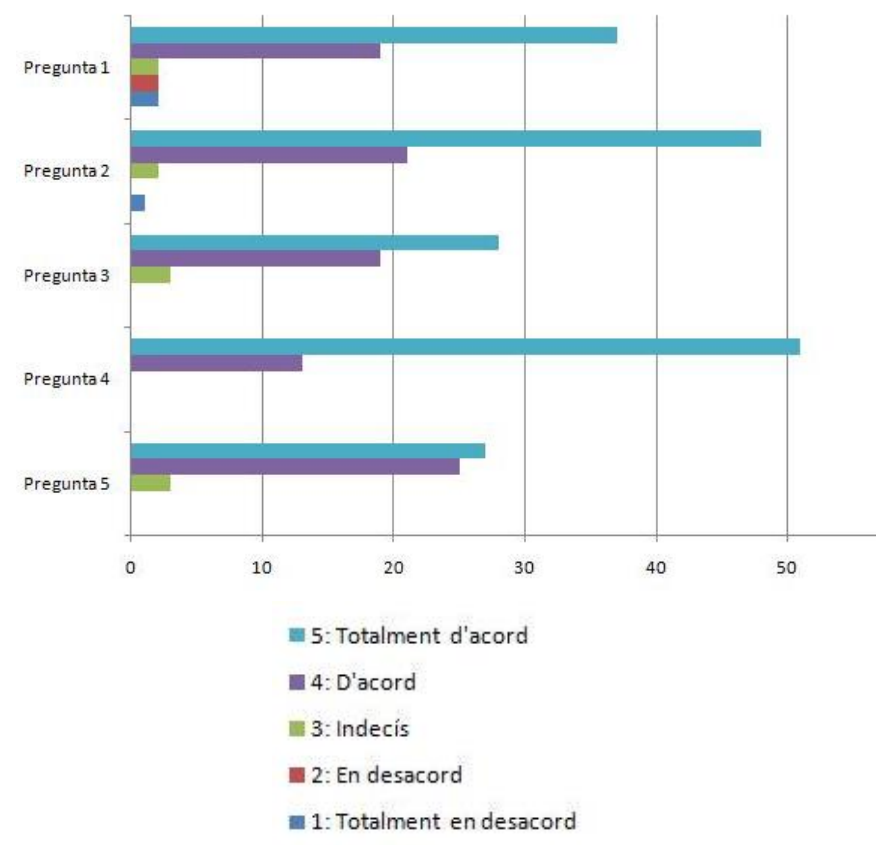

Figura 6. Gràfic de barres amb el resultat del qüestionari en línia als alumnes en relació a l'activitat 2.

\section{CONCLUSIONS I PROPOSTES DE MILLORA}

Per tal de veure si la nostra proposta de millora educativa ha resultat positiva tornarem a l'objectiu que ens vam plantejar:

Incrementar tant la participació com la motivació dels alumnes en les classes de Física i Química $i$ fer que els alumnes relacionen allò que estan estudiant amb la seva vida quotidiana.

L'ambient que es va crear en la realització de l'activitat va ser molt positiu. Als equips tots tenien la voluntat i la consciència d'haver d'estudiar per al seu benefici però també per al benefici de tot l'equip.

Les conclusions de tots els resultats analitzats són molt positives. No seria cap atreviment dir que aquesta metodologia ha complit amb les expectatives inicials. Tots els estudiants han participat de les classes i han gaudit mentre aprenien junts. Malgrat que la reacció en ser explicada la metodologia no va ser massa positiva i que en la primera sessió alguns no havien estudiat, a mesura que avancàvem en les jornades la predisposició era més bona. Repetir el Joc Concurs va servir per afermar tant els equips de treball com la metodologia.

A més a més, haver realitzat aquesta acció també ha fet que la gran majoria d'alumnes hagen millorat les seues qualificacions respecte als temes anteriors, tal i com va confirmar la tutora. Açò, ens fa pensar que també s'han complert els objectius propis de la matèria que ens havíem plantejat.

Malgrat tots els indicadors favorables als quals ens hem referit, els alumnes no han fet ús adequat de la plataforma virtual Google Sites per consultar aspectes relacionats amb les activitats. S'hauria de pensar en una tasca obligatòria i avaluable. Així, ${ }^{6}$ Ber a treballar la competència digital, augmentar l'interès dels alumnes per aquesta ferramenta i motivar-los a utilitzar-la, es podria crear una secció en la web on els estudiants "pujaren" una fitxa de seguiment de les sessions del Joc-Concurs (figura 7 ), anotant per exemple les persones del grup que han estat presents, els dubtes que han tingut i si els han resolt, què han aprés en cada sessió i què els falta per repassar, etc.. D'aquesta manera, tant els alumnes com la professora també podrien fer un seguiment més directe del que s'està aprenent, i detectar qualsevol problema o mal funcionament de l'equip. Amb aquesta millora, el pla d'acció quedaria modificat i preparat per ser aplicat en el nou cicle d'Investigació-acció. 


\begin{tabular}{|l|l|}
\hline \multicolumn{1}{|c}{ Fitxa de seguiment } \\
\hline Membres del grup....... \\
Sessió ....... \\
\hline Persones del grup que hem estat \\
\hline Algú del grup tenia dubtes? Quins eren els dubtes? \\
\hline Heu resolt els dubtes? \\
\hline Què has après en aquesta sessió? \\
\hline Quins conceptes has de repassar? \\
\hline
\end{tabular}

Figura 7. Exemple de la fitxa de seguiment de les sessions Joc-Concurs.

\section{BIBLIOGRAFIA}

BARKLEY, E. F. (2007). Técnicas de aprendizaje colaborativo (Morata) Madrid.

BARRADO, C. ; GALLEGO, I. I VALERO-GARCÍA, M. (1999). Usemos las encuestas a nuestros alumnos para mejorar nuestra docencia. Departament d'Arquitectura de Computadors. Universitat Politècnica de Catalunya. España.

BRUNS, A., \& HUMPHREYS, S. (2005). Wikis in teaching and assessment: the M/C Cyclopedia Project (Brisbane) Australia.

DECRET 112/2007, de 20 de juliol, del Consell, pel qual s'estableix el currículum de l'Educació Secundària Obligatòria a la Comunitat Valenciana. [2007/9717]

DOMINGO, J. (2008). El aprendizaje cooperativo. Cuadernos de Trabajo Social, 21, 231-246.

GRACIELA, N. I SÁNCHEZ, L. (2010). El aburrimiento en clases. Procesos Psicológicos y Socialels, Volumen(6)

MAQUÉS ANDRÉS, M. I FERNÁNDEZBERRUECO, R. (2011). Investigación Práctica en Educación: Investigación-Acción. XVII
Jornadas de Enseñanza Universitaria de la Informática (JENUI 2011), Sevilla, España.

MONFERRER, J. L., \& FORCANO, A. (2014). El aprendizaje colaborativo y las TIC en clase de física. Alambique, 76, 37-44.

MOLINER, O.; SANCHIZ, M.L. Y SALES, A (2009) Estrategias metodológicas. Material docente de la asignatura Procesos y contextos educativos (material inédito)

NEFF, A. I ALTRES (2010). Bend it, Stretch it, Hammer it, Break it. Materials Chemistry Applied, Fall, Volum(19), № 2.

PASCARELLA, E., \& TERENZINI, P. (1991). How college affects students (J.-B. H. \& A. Education) San Francisco.

PUJOLÀS, P. (2003). El aprendizaje cooperativo: Algunas ideas prácticas. Universidad de Vic.

SPENCER, K. I HIGH, J. (2002). Kagan Structures for English Language Learners. ESL MAGAZINE. Julio/Agosto 2002, 10-11.

WALDEGG, G. (2002). El uso de las nuevas tecnologías para la enseñanza y el aprendizaje de las ciencias. Revista Electrónica de Investigación Educativa, 4

[1] Disponible a:

https://sites.google.com/a/uji.es/la-taula-periodica/

[2] Disponible a:

https://sites.google.com/a/uji.es/la-taulaperiodica/proces/activitat-1

[3] Disponible a:

https://sites.google.com/a/uji.es/la-taulaperiodica/proces/activitat-2

[4] Disponible a:

https://docs.google.com/a/uji.es/forms/d/1hYx85afN L76k5Tz9xLmpC0flhC5aLLbV6VMOSeoJMew/v iewform

[5] Disponible a:

https://docs.google.com/a/uji.es/forms/d/1FBs4a5u ZSVjfMzuKty6v0AKCa6nZsrIMheentfaFWI/viewf orm 